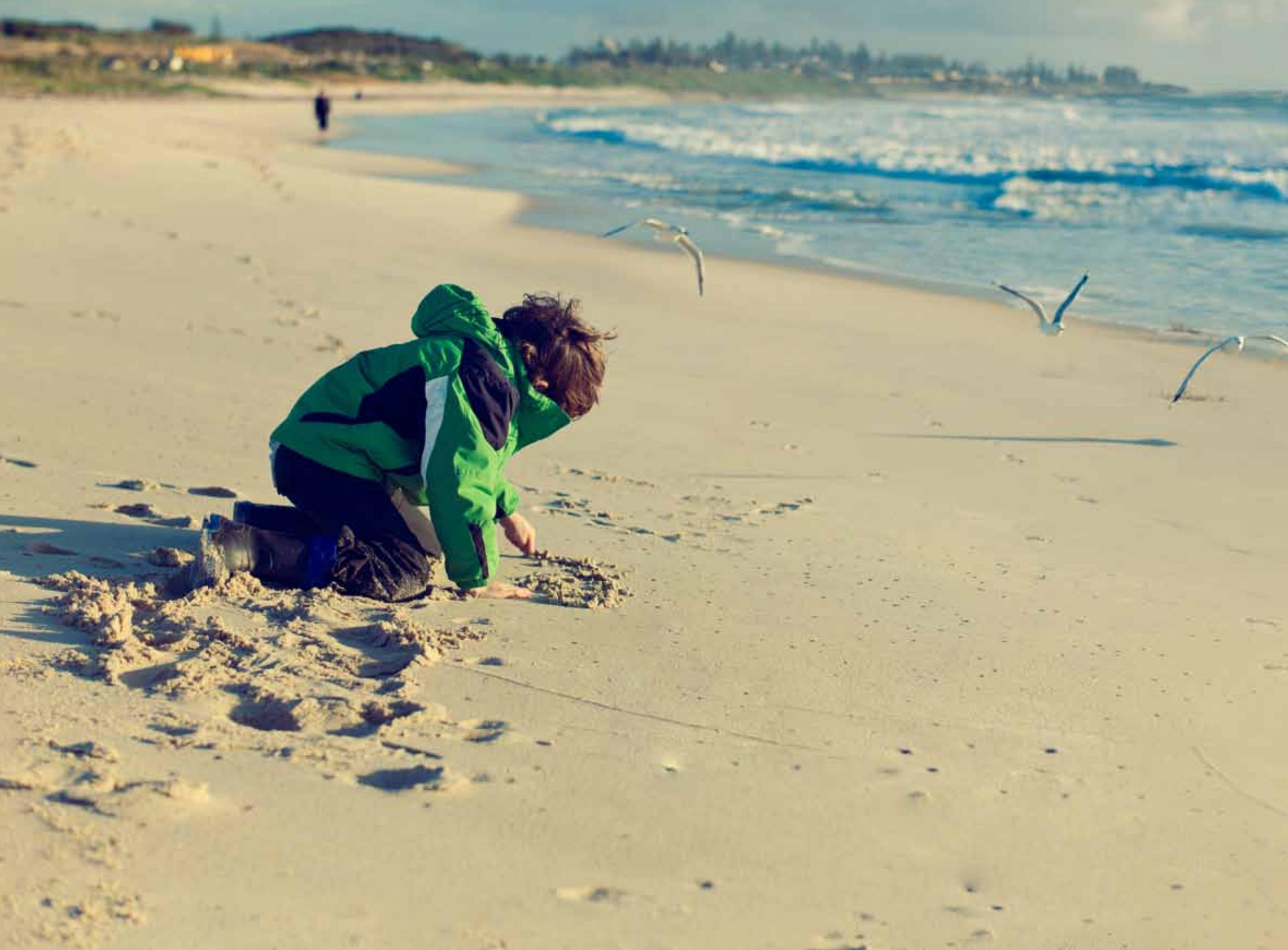




\section{Advance Australia Fair}

Does civilisation only exist by geological consent? The previous 10 chapters in this book suggest that this statement might be true, by showing the manifold ways in which the geology of the Australian continent, and its marine extensions, has shaped Australia and continues to shape the people. This concluding chapter looks briefly at the opportunities and challenges that Australian geology creates for the future of this nation.

Chris Pigram, ${ }^{1}$ Richard S Blewett, ${ }^{1}$ Keith M Scott,${ }^{2,3}$ Phil L McFadden, ${ }^{4}$ David C Champion, ${ }^{1}$ Phil R Cummins ${ }^{1,2}$

${ }^{1}$ Geoscience Australia; ${ }^{2}$ Research School of Earth Sciences, Australian National University; ${ }^{3}$ CSIRO Earth Science and Resource Engineering; ${ }^{4}$ consultant 


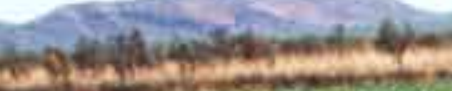

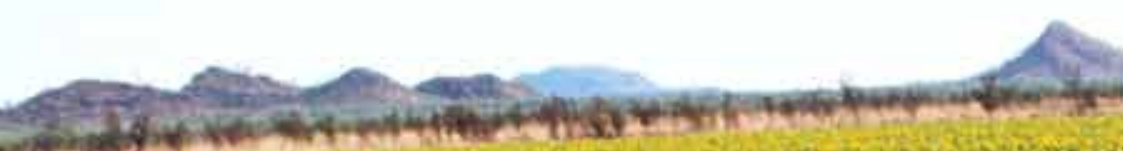

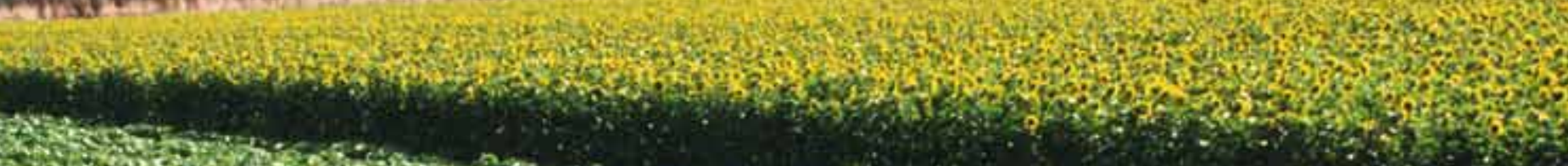

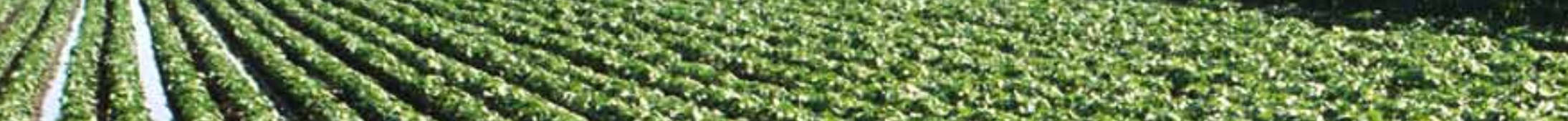

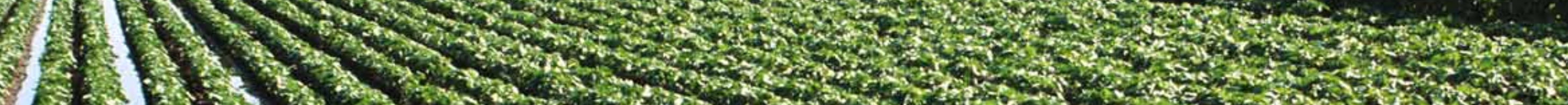

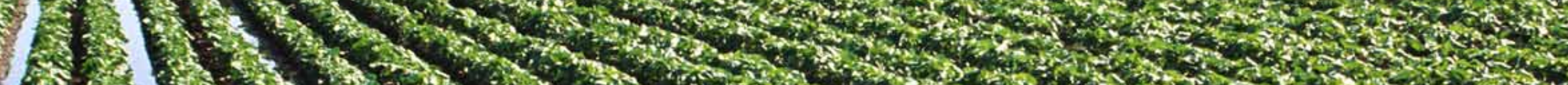

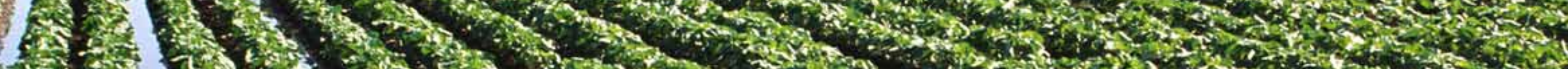

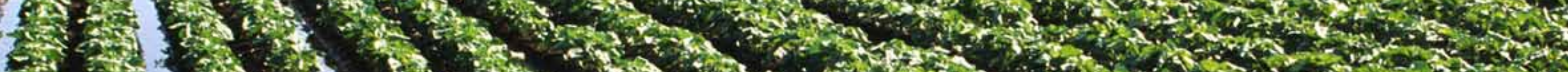

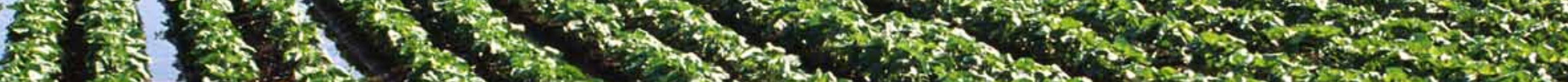

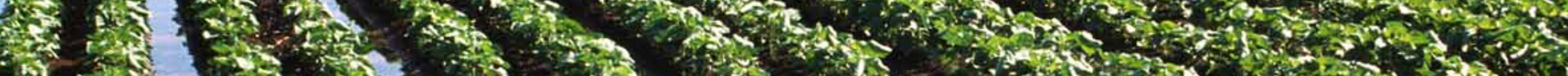

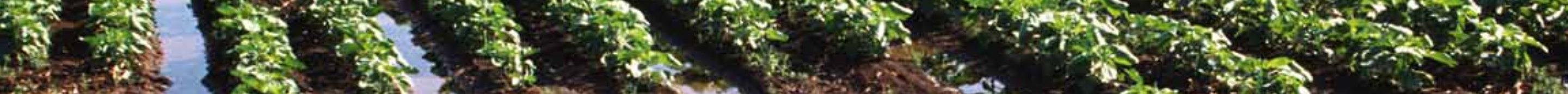

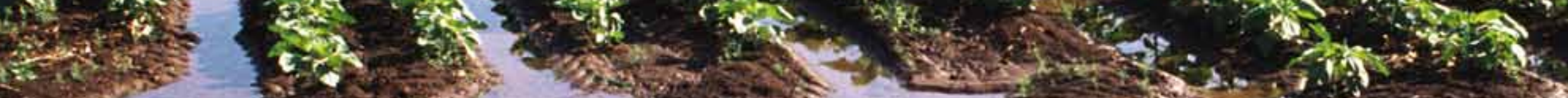

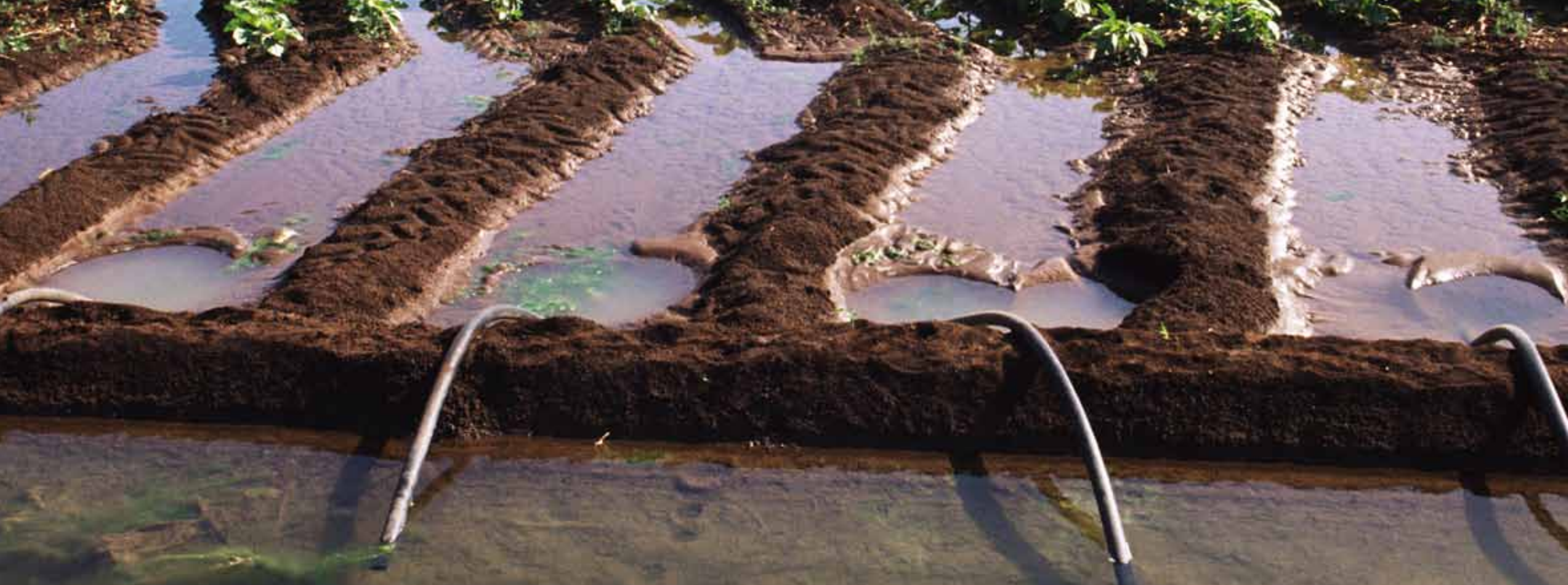




\section{Lucky country?}

The social commentator Donald Horne coined the phrase 'The Lucky Country' to describe Australia - a phrase he used ironically, despite its common misquotation today. Nevertheless, in terms of geology, the country has been lucky, as the continent is well endowed with nature's gifts— gifts that have fundamentally shaped the fortunes of the Australian people, as shown in earlier chapters of this book. In navigating the 21st century and beyond, Australians will be influenced by factors such as demographics, politics and economics, but the underlying legacy of Australia's geology will continue to shape the nation.

Current and future societal challenges are and will be varied (Box 11.1), but they are intimately linked with the stewardship of the environment, the sustainable availability of resources (food, fibre, water, energy and minerals) and community safety (Figure 11.1). Successfully meeting these challenges will require an even deeper knowledge and understanding of Earth as a system of complex interrelationships.

The global population is rising rapidly. Standards of living are also rising, making increasing demands on the finite resources of Earth. Australia is not immune to this and, in this developed nation, Australians are high per-capita consumers of resources (Chapter 1). With a $2 \%$ population growth rate in recent years, the projected population of Australia is estimated to be more than 35 million by the middle of the 21 st century. Such a population increase will have a substantial impact on water, energy and food security, with strong competition between environmental concerns and economic

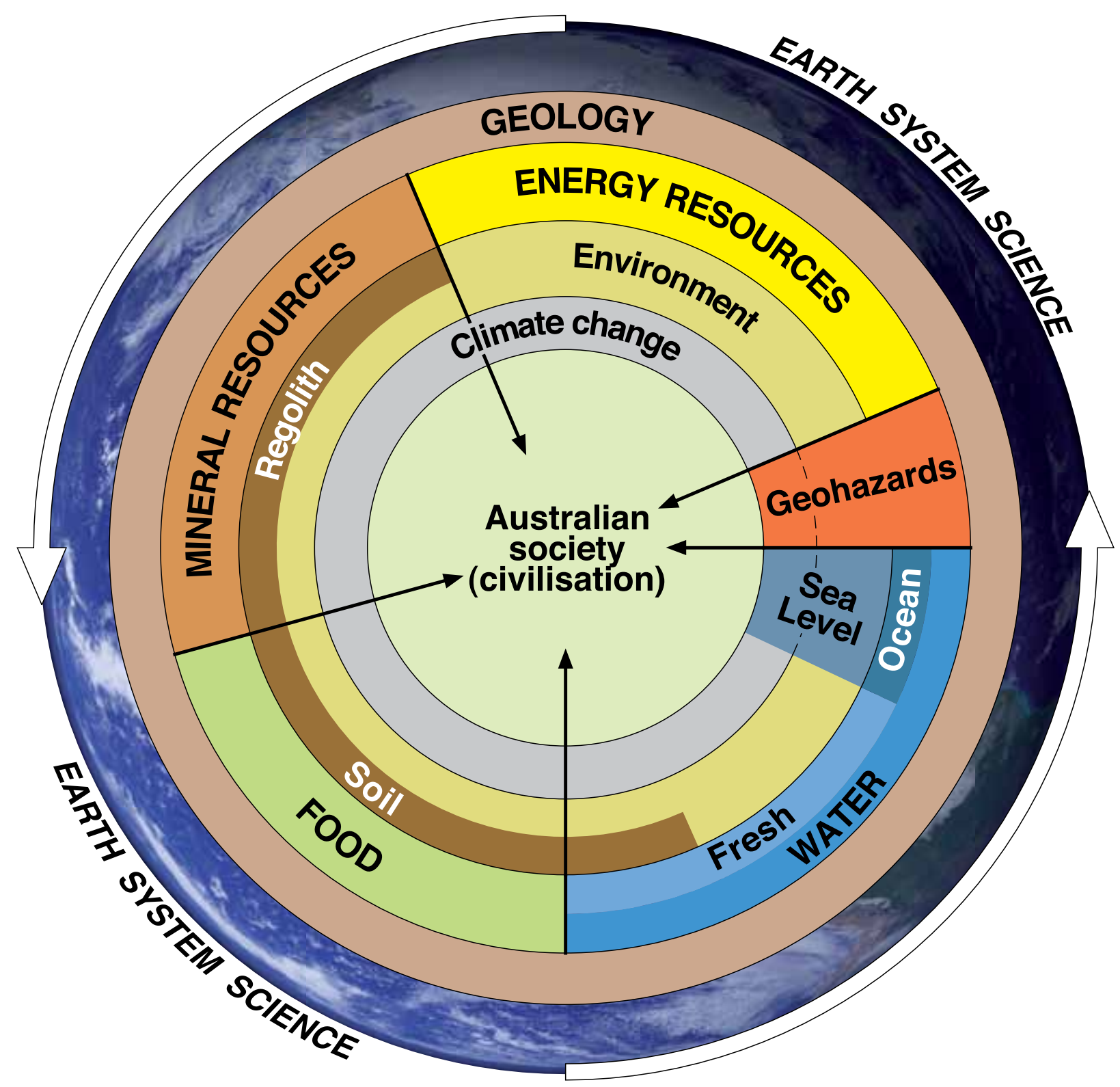

growth. Increasing populations also add to the level of exposure to natural hazards, which may increase in magnitude and frequency with climate change. Many of these challenges have solutions, if somewhat partial, rooted in Australia's geological heritage and in the Earth system (Chapter 2).
Figure 11.1: Interrelationship between sustainable civilisation and the Earth system.

- Opposite: Irrigating bean and sunflower crops. o Getty Images [Radius Images] 


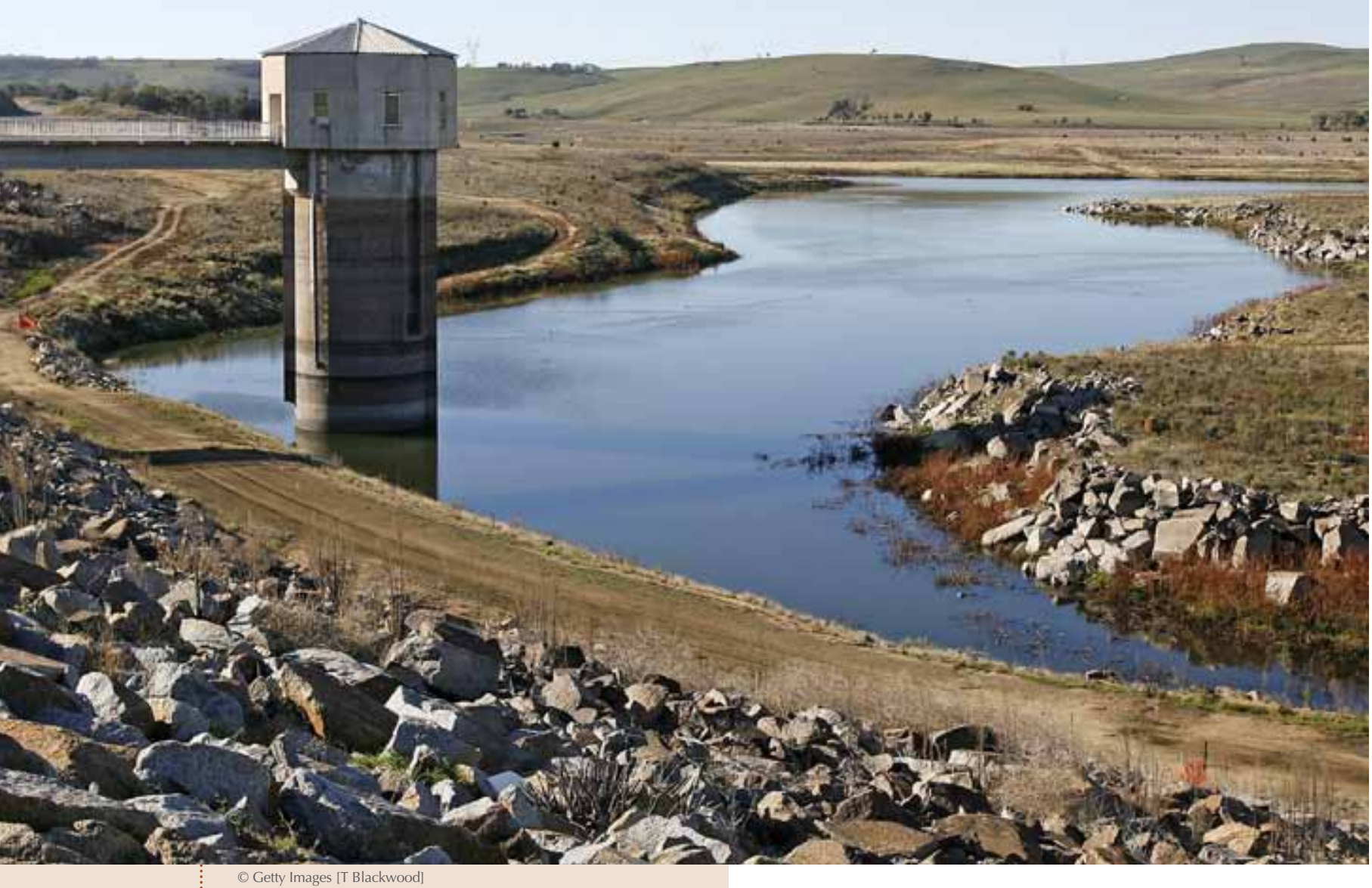

o Pejar Dam, one of the dams supplying water to Goulburn, New South Wales. Photograph taken in 2006 at the height of the drought.

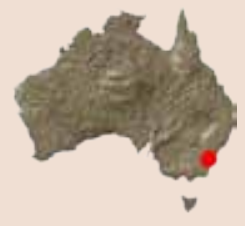

\section{Food, fibre and water}

As a large country with a diversity of soils and climate zones, Australia supplies food to more than 60 million people. The actual available land for 'agricultural Australia' is not that large; it is similar in size to the area of France, but with much lower productivity. Australia's geological history has left the continent with a deep regolith and a landscape that is old, flat and red (Chapter 5). As a consequence, most Australian soils tend to be fragile, prone to salinity, and depleted in trace elements essential for growing food. The carrying capacity of the land is low and not necessarily amenable to easy 'fixes', such as the addition of fertilisers. Furthermore, past agricultural practices, especially the large-scale clearing of native vegetation, have degraded the environment, leading to elevated water-tables and widespread salinity (Chapter 7). Overgrazing and overclearing, coupled with drought and strong winds, result in dust storms and large losses of valuable topsoil. The growing urban sprawl around Australia's largest cities is adding to the problem as more of the nation's fertile soils close to the consumers become locked away beneath concrete (Chapters 5 and 10).

Water security is vital to civilisation. Human history is littered with once-thriving societies that foundered due to lack of water. Australia is a dry continent with a large arid zone. Our pattern of settlement and development has been, and is, strongly linked to rainfall distribution. Despite this, Australians are large household consumers of water, using more per capita than all other western countries except New Zealand, Canada and the United States. Given Australia's projected future population increases, will the high use of water be sustainable? Although there is a heavy reliance on surface water resources in Australia, the continent has abundant groundwater resources. These are, however, not always located where the demand is, nor are they necessarily of high potable quality, nor are they all renewable. In places, they have been poorly managed, with excessive groundwater use being associated with land subsidence and seawater incursion into freshwater coastal aquifers (Chapter 7).

Competition for water, and how this precious resource is allocated between different interests, is a significant challenge for governments and regulators. One example is balancing the activities of the coal-seam gas industry with the desire 


\section{FUTURE CHALLENGES (вох 11.1)}

- Australia is the driest inhabited continent, and the soils are thin and fragile. There is ongoing demographic and economic pressure to produce more food and fibre. The nation's challenge is to effectively and sustainably manage the soils and water (particularly groundwater) of Australia in an environment of growing population and climate change. With the increasing likelihood of groundwater being mined, we must learn from our experience of past resources exploitation to develop, and give real meaning to, the concept of sustainable yield for groundwater use.

- Australia has abundant energy resources. The nation's challenge is to determine the balance of its energy resources in an increasingly carbon- and water-constrained world in ways that best meet the needs of a sparsely populated country in a region that is rapidly growing and industrialising.

- Australia's mineral resources are large, but they are finite. The nation's challenge is to ensure an ongoing pipeline of discovery and development to meet the needs of the domestic economy and the demands from a growing neighbourhood.

- Australia has reduced the risks to people of natural hazard events by nearly a factor of 100 in the past 150 years. The economic costs, however, have been increasing steadily. This increase is driven mainly by increases in exposure (population and value of assets).
The prospect of increasing risks from climate change, the interdependency of the world economy and the growing importance of Australia's role in the Australasian region all indicate that natural hazards will continue to be a significant challenge to the nation.

- There is much we do not know about the Australian continent. Many of the nation's challenges involve the environment, sustainable availability of resources and community safety; these are linked to Earth system processes. Meeting the challenges will mean that earth scientists will need to study their field in the context of a larger and more intricate Earth system.

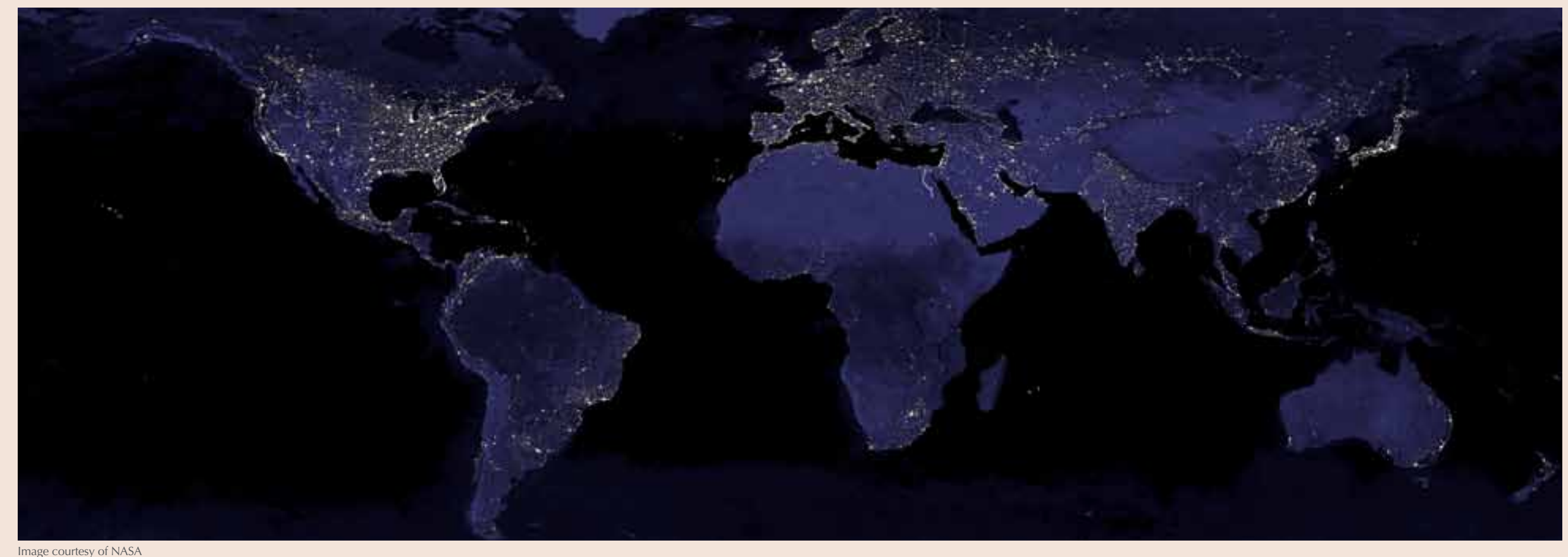




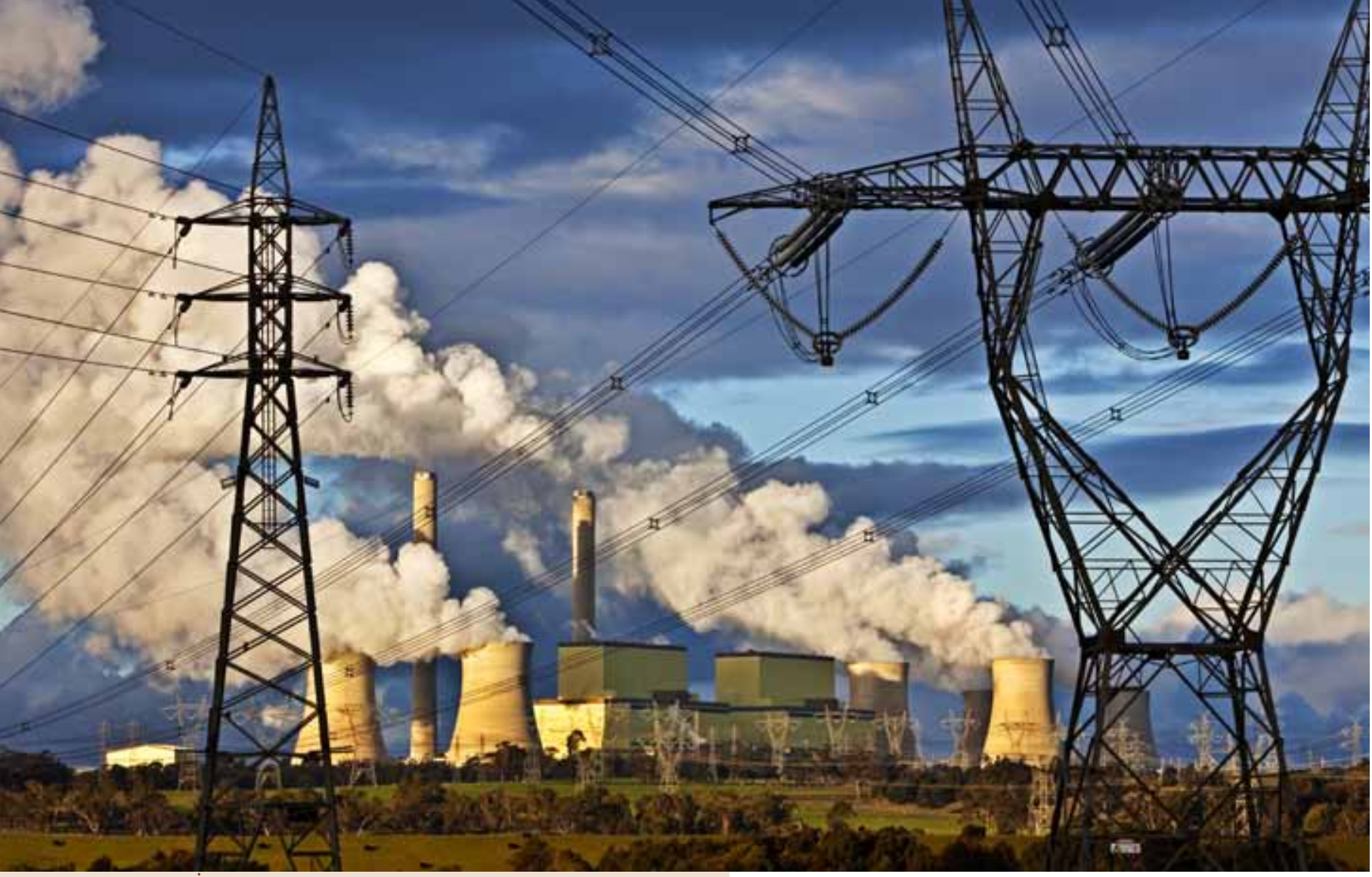

(o Getty Images JW Banagan]

Coal-fired power station, Traralgon Victoria. to preserve water quality and aquifer levels for agricultural use and the environment. Competition can also occur between the requirements of agriculture and urban centres for a reliable supply of water and the needs of the environment, such as in the Murray-Darling Basin. In all these examples, understanding the hydrological system connecting the surface water with the groundwater, the distribution of aquifers and the geological framework across the entire catchment is crucial for informed and sustainable management decisions.

Images of town dams reduced to a muddy puddle, and trucks carting water, highlight the vital need for water security. One response by state governments around the country was to build, or put plans in place to build, desalination plants. Technology has driven down the costs and improved the efficiency of desalination. Nevertheless, the process is a large consumer of energy, and the saline by-product needs to be disposed of in ways that do not impact marine ecosystems. Where will this energy for desalination come from in ways that do not pollute? How can the saline by-product be disposed of sustainably? These are questions that go to the heart of the interrelated energy-carbonwater system of Earth.

\section{Energy and power}

Economic growth, and the development of all nations, has relied on access to cheap energy. A remarkable outcome of this development has been the transformation of lives of billions of people from poverty to wealth, and long and healthy life spans. Energy is all around us; it is the power that can be generated from it and made to do work that has transformed humanity. Most of our power is derived from energy-dense fossil fuels: coal, oil and gas (Chapters 4 and 9). Atmospheric pollution (greenhouse gases) from burning fossil fuels is an externality not generally factored into the costs of these energy sources. Nations will increasingly be required to lower their carbon emissions through efficiency measures and alternative sources of energy that produce less $\mathrm{CO}_{2}$ (Box 11.2, Chapter 10).

Australia is a high per-capita producer of $\mathrm{CO}_{2}$, with most coming from electricity generation and transport. Australia's geology has ensured that vast amounts of high-quality coal were deposited in Permian basins close to where the nation's main population centres were subsequently established millions of years later. It is no surprise, therefore, that about $70 \%$ of Australia's electricity is generated by burning coal (Chapter 9). Australia is also a 


\section{- CARBON DIOXIDE CAPTURE AND STORAGE}

The energy sector produces around $76 \%$ of Australia's $\mathrm{CO}_{2}$ emissions (417 Mt of $\mathrm{CO}_{2}$-equivalents in 2010), of which electricity generation makes up $36 \%$. A carbon dioxide capture and storage (CCS) strategy involves (1) capture of the $\mathrm{CO}_{2}$ generated from a stationary source point (e.g. power station); (2) transport of the $\mathrm{CO}_{2}$ to the site of injection through pipelines or, on a smaller scale, by road, rail or ship; and (3) storage by injecting the $\mathrm{CO}_{2}$ into a porous, permeable reservoir (e.g. in sandstone) that is at sufficient depth (generally $>800 \mathrm{~m}$ ) to keep the $\mathrm{CO}_{2}$ in a supercritical, fluid state (Figure B11.1). Potentially, such a strategy could reduce emissions into the atmosphere from $\mathrm{CO}_{2}$ source locations (fossil fuel power generation and industrial processing) by more than $80 \%$.

These reservoirs generally contain saline water or other fluids, such as oil, natural gas and naturally occurring $\mathrm{CO}_{2}$. To be suitable for $\mathrm{CO}_{2}$ storage, the reservoir must be overlain by an impermeable sealing rock such as mudstone, which will prevent the escape of fluids. This is critical because the injected $\mathrm{CO}_{2}$ is buoyant and will act like any naturally occurring gas, gradually rising from where it is injected until it meets the sealing rock. The $\mathrm{CO}_{2}$ will be trapped in the reservoir by dissolving into the formation water and, over time, and depending on the geochemistry of the rock, will form carbonate-rich minerals within the reservoir.

The National Carbon Mapping and Infrastructure Plan (2010) confirmed that Australia's sedimentary basins have sufficient storage space for large-scale projects. However, although in some cases there is a good match of emission source with proximal storage sites (e.g. Gippsland and Perth basins), in many places suitable pore space is either not available or is some distance from the emission point (e.g. Sydney and southeast Queensland).

There are currently two CCS projects in Australia, both of which are located in petroleum basins with gas production. In the Otway Basin, western Victoria, $\mathrm{CO}_{2}$ sourced from a natural $\mathrm{CO}_{2}$-rich gas field nearby has been injected and stored $2 \mathrm{~km}$ underground. The reservoir lies within a Cretaceous rift sequence in the Waarre Formation, which also hosts significant commercial gas deposits. The project has demonstrated the feasibility of injection and storage of $\mathrm{CO}_{2}$ in Australia, as well as the ability to model $\mathrm{CO}_{2}$ plume movement, and monitor its chemical and physical changes within the reservoir. Extensive monitoring of the $\mathrm{CO}_{2}$ throughout and after injection has proven the project to be very successful to date.

The Gorgon CCS project, located in the Carnarvon Basin, Western Australia, involves the removal and geological storage of reservoir $\mathrm{CO}_{2}$ from the natural gas fields in the offshore Greater Gorgon area. The $\mathrm{CO}_{2}$ will be injected into the Dupuy Formation, deep below Barrow Island. This formation was deposited in a deep marine slope setting and is sealed by a regional deltaic unit, the Basal Barrow Group Shale. The sedimentological pattern of an excellent reservoir-regional seal combination is repeated in several places across the North West Shelf in Jurassic to Late Cretaceous sequences (Chapter 4). This makes the offshore shelf a highly prospective area for geological storage for future liquefied natural gas projects in the region.

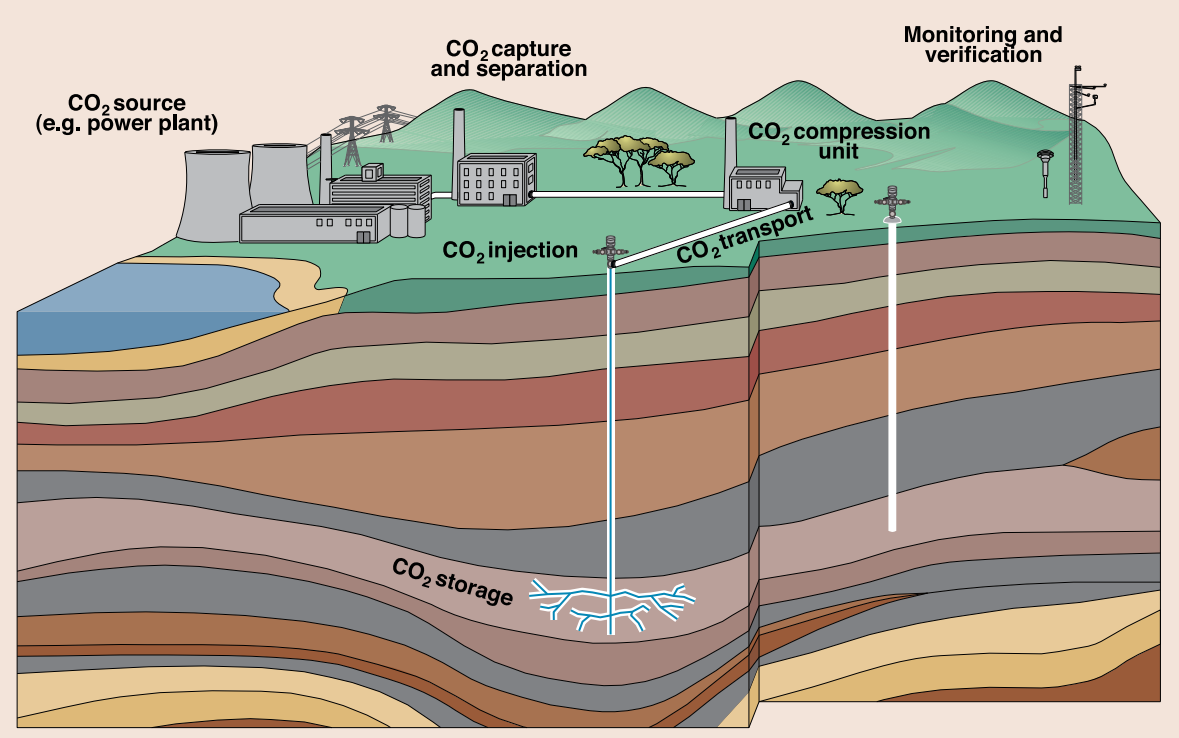

Figure B11.2: The process of capturing carbon dioxide from a power plant, compressing it and injecting it deep underground in rocks. (Source: CO2CRC) 
large country with a dispersed population largely living in expansive sprawling cities, making both long- and, particularly, short-distance transport of goods and people a necessity of modern living.

Reducing Australia's dependence on coal will be a challenge economically (coal is readily available and cheap) and a challenge technologically (what to replace it with). This challenge applies not just to the Australian people but to the many export industries that depend on access to cheap power, such as aluminium refineries. One 'geosolution' that might satisfy both challenges is carbon capture and storage, which captures emissions at the source and sequesters them in nearby basins (Box 11.2). Australia would benefit enormously if carbon capture and storage works economically as planned. The economy is highly dependent on coal export earnings, which are forecasted by the Bureau of Resources and Energy Economics at \$53 B for 2011-12. With carbon capture and storage, future importing nations would have both a supply of energy and a means of disposing of their $\mathrm{CO}_{2}$ waste.

The attributes of a good basin for carbon capture and storage are similar to those of oil- and gas-producing basins-that is, a porous and permeable reservoir covered by a seal at a suitable depth to keep $\mathrm{CO}_{2}$ in supercritical-liquid form. The main coal basins of New South Wales and Queensland do not have these attributes. Most of them are tight and impermeable, making injection and storage of fluid problematic. As a result, most current research on carbon capture and storage in Australia is testing the main oil- and gas-producing basins in Western Australia and Victoria. The search is on, however, for other suitable basins, such as the Surat Basin in Queensland, as well as improvements to the viability of the technology.

Australia's geology also bequeathed the nation another abundant source of energy — both conventional and unconventional gas. Australia is on track to be the second largest exporter of liquefied natural gas (LNG). Burning gas rather than oil or coal has the benefit of lower $\mathrm{CO}_{2}$ emissions, so that it is commonly viewed as a transitional source of energy before more widespread usage of non- $\mathrm{CO}_{2}$ producing options in the future.

In the United States, energy security concerns and the development of new technology have seen the emergence of a major new industry in unconventional (shale) gas, which is predicted to make the country a net energy exporter. The development of these gas resources has not been without its critics, because the gas is extracted by a hydraulic fracturing process that increases the permeability of the tight reservoirs. Regulators in the United States are dealing with conflicting interests: those of energy security and new jobs, and protection of the environment and human health.

Australia has been slower than the United States to unlock its unconventional gas resources. The coal basins of eastern Australia also host major coal-seam gas resources (Chapter 9). The increasing demand for domestic energy, jobs and export earnings will likely mean that these unconventional gas resources will be further developed. Unlike offshore gas, some of the best coal-seam gas prospects are located close to communities or beneath valuable farmland. Communities are concerned about loss of or damage to land, pollution and changes to the groundwater aquifers. Meeting these community concerns requires a much greater understanding of the three-dimensional geology of the basins, as well as the interrelationship between the groundwater and the gas resources.

Geology has also bequeathed Australia the world's largest reserves of uranium $(\mathrm{U})$, as well as significant reserves of thorium (Th). Partly because of the easy availability of alternative energy sources, Australia does not currently use its nuclear potential to generate electricity; rather, $U$ is exported to other countries for their domestic power generation (Chapter 10). The merits of nuclear power are as much about politics and community as they are about geology. Australia is also fortunate to have an abundance of Th. Thorium has numerous advantages over $\mathrm{U}$, including the difficulty in producing nuclear weapons using Th. Thorium is three to five times more abundant than $\mathrm{U}$, and can generate more energy per unit mass. Unfortunately, there are no commercial-scale nuclear reactors that can use Th. Although there is no use for it, Th is a by-product of some mineral-sand operations. The Th by-product is diluted with gangue sand and buried, rendering it uneconomic, but safe.

A less contentious source of radioactivity is contained within many of the Proterozoic and some Carboniferous granites of Australia. These are especially well endowed in heat-producing elements and, when buried beneath insulating basins, they are ideal sources of carbon-free geothermal energy, such as in the Cooper Basin (SA). The location of many geothermal plays is now known, but the 
process of economically extracting the heat and getting it to market poses continuing geological, geochemical and engineering challenges. The potential of geothermal energy in Australia is enormous. If only $1 \%$ of the geothermal energy contained in the upper $5 \mathrm{~km}$ of Australia's crust could be extracted, there would be more than $30 \mathrm{ka}$ of supply at current usage. Even a more realistic $0.01 \%$ gives more than $3 \mathrm{ka}$ of supply. Technological and engineering advances have yet to enable this vast resource to be effectively tapped, but, when they do, Australia might be able to power itself in a low-carbon and sustainable way for thousands of years. Even in the use of truly renewable energy (e.g. hydroelectric, solar, tidal and wind), Australia's position on the globe provides it with a range of climates and latitudinal variation for all of these to potentially make greater contributions to energy requirements in the future.

Although Australia has an abundance of energy, it is short of oil. So is the rest of the world. The world's 'peak oil' may indeed have passed in 2005; Australia's oil production peaked in 2000-01. World oil production appears 'stuck' at around 75 million barrels per day, meaning that high oil prices will remain if demand keeps rising, as it is forecast to do. All is not lost for Australia's oil. The vast basins fringing the southern margin of the continent are largely untested, as are the basins in the remote eastern frontiers, (Chapter 4). Australia also has significant demonstrated resources of unconventional hydrocarbon sources, such as shale oil. These resources remain undeveloped, mostly because of economic and environmental constraints.
The future is difficult to predict, but we can be certain of increasing domestic and overseas demands for energy. Only time will tell what mix Australia chooses. The Australian people are indeed lucky to have such a favourable geological legacy of energy choices.

\section{Mineral resources}

The economic growth in China and India, and concerns of Japan and Korea about resource security over the past decade have had a major impact on Australia's economy and trade relationships. Demand for Australian minerals and energy resources has created a boom for the resources sector, and led to closer economic links with Asia, particularly China (Chapter 9). National export earnings from minerals and energy amounted to $\$ 190$ B in 2011, and much of the manufacturing export income was also resources related (e.g. refining and smelting).

A positive consequence of this demand has been a strong domestic economy, despite the difficulties facing many OECD countries. A negative consequence has been the impact on other sectors of the economy. Demand for Australian resources, along with relatively high interest rates (by international standards), has driven the Australian dollar above parity with the United States dollar (US\$1.03 average for 2011). The Australian Treasury predicts that the Australian dollar is likely to remain high for a number of years. As a result, the non-resources sectors of the economy, which have been suffering since the mid 2000s, will probably continue to do so as Australian goods and services remain expensive on world terms. 

hazard environment. Extreme events, such as tropical cyclones, floods, severe storms, bushfires, earthquakes and tsunamis, however, can threaten Australia's wellbeing. Indeed, natural hazards cost Australia more than $1 \%$ of its gross domestic product annually, with some years experiencing large-scale natural disasters that drive this cost far above the average.

Tropical cyclones are often regarded as the most devastating weather-related hazard, causing severe winds and storm surge that can have major impacts over large areas. Cyclone Tracy destroyed the city of Darwin in 1974, an event still ingrained in the psyche of many Australians, and one that changed the building codes. Although the area is sparsely populated, there are large infrastructure facilities located adjacent to the northwest coast, such as the gas production on the North West Shelf and iron ore export from the Pilbara Craton. These are significant sites in terms of export-earning capacity of the nation, and are vulnerable to the impacts of tropical cyclones, as well as tsunamis.

Floods are, on average, the most costly of Australia's natural hazards, accounting for roughly $30 \%$ of the total loss due to all hazards. No wonder Australia was called by Dorothea Mackellar 'the land of droughts and flooding rains' (Chapter 1). Although Australia is the driest inhabited continent, periods of heavy rainfall—typically in La Niña yearscan turn vast areas of the arid centre into an inland sea for weeks or months at a time. More short-duration, rapid-onset floods tend to occur in the northern and eastern coastal regions, with several of the main population centres along the eastern seaboard having historical experience of more than one major urban flooding event.

Advance Australia Fair
A positive effect from these flood events has been the replenishment of parched aquifers and dams, and the flushing of river systems.

Bushfires have been an intrinsic element of the Australian environment since long before humans arrived, and Aboriginal fire-stick agriculture further shaped the environment to one dominated by fire-adapted flora (Chapter 3). Many native plants contain volatile oils and readily burn in the hot, dry conditions that prevail during the Australian summer, particularly in El Niño years. Such fires cause considerable loss of life and property on the urban fringes of cities in Australia's south, where homes are in close proximity to the bush. Occasionally, such fires penetrate farther into suburban areas, where the loss of life and property can be severe.

Victorian bushfire aftermath 2009.
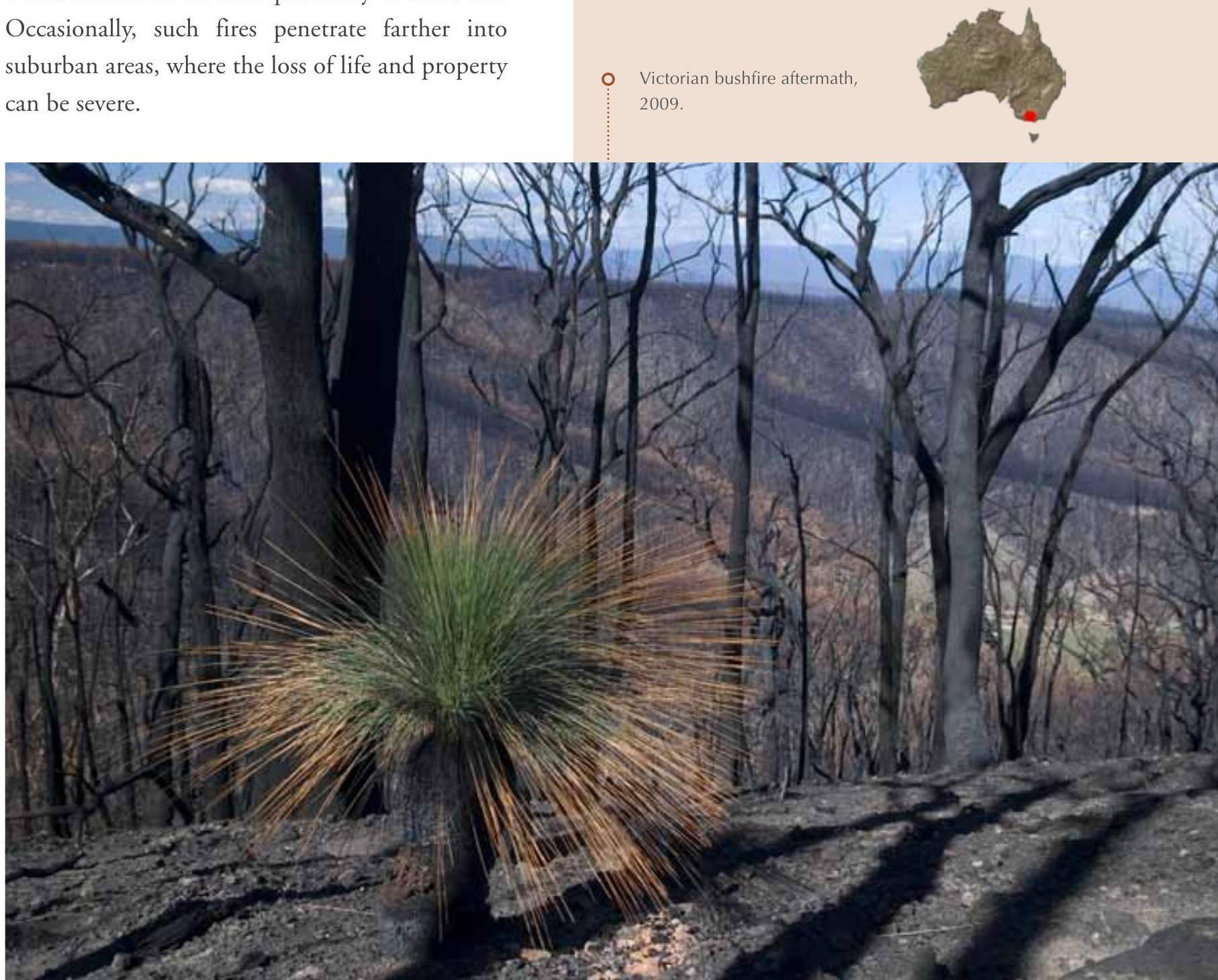
Geological hazards that pose a threat to Australia's wellbeing include earthquakes and tsunamis. Due to continental Australia's position remote from active tectonic plate margins, earthquake activity is much lower than in neighbouring countries. This low rate of earthquake activity has led to a sense of complacency among Australians. However, that complacency was shattered by a magnitude 5.6 earthquake in Newcastle on 28 December 1989. This resulted in 13 deaths, 160 injuries and an estimated \$4 B total economic loss. It changed the building code in Australia to one with an appropriate seismic loading standard. However, Australian cities still contain a substantial number of pre-1989 buildings, particularly brick buildings that are not designed to withstand earthquakes. Thus, the fear remains that, if an earthquake as large as, say, the 1968 Meckering (WA) earthquake (magnitude 6.8) were to occur near one of Australia's major population centres, the impact could be catastrophic. Australians can hope that the chances of such an event occurring are sufficiently low that there will be time to replace most of the older buildings before it occurs. This is a clear example of how humans tend to judge risk from the context of their own life span: 'We have never seen that happen before, so it won't happen here'. Things that seem rare in human experience are often common in the geological time-scale, thereby underlining the ongoing need to significantly improve our understanding of geological processes and their resulting risks to us.

Australia's distance from subduction zones to the north and east have mitigated the impact of large historical tsunamis (Chapter 6). However, the recent occurrence of large earthquakes, such as the 2004 Sumatra-Andaman and 2011 Tohoku earthquakes in subduction zones that were not considered to support such large events, demonstrates the danger of relying on the immediate historical record for assessing hazard. If subduction zones such as those off Java or in the Puysegur Trench south of New Zealand (Figure 2.1) can support earthquakes much larger than historical experience suggests, then the northwestern and southeastern coasts of Australia could face a considerable tsunami threat. Fortunately for Australians, these, and other subduction zones, are at least 2.5 hours tsunami travel time away, which is enough time for the Australian Tsunami Warning System to alert coastal populations.

How might climate change influence the impacts from weather-related hazards in the future? Most climate models predict that southeastern Australia will become hotter and drier, leading to a higher risk of bushfires. The models also suggest that tropical cyclone tracks will move further south (Chapter 6), exposing larger populations that have lower standard building codes to potentially devastating cyclonic events. Rising sea-levels could increase coastal inundation extremes, creating severe impacts on the Australian community (housing and infrastructure), much of which is

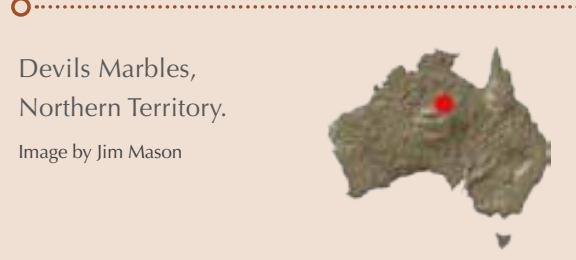

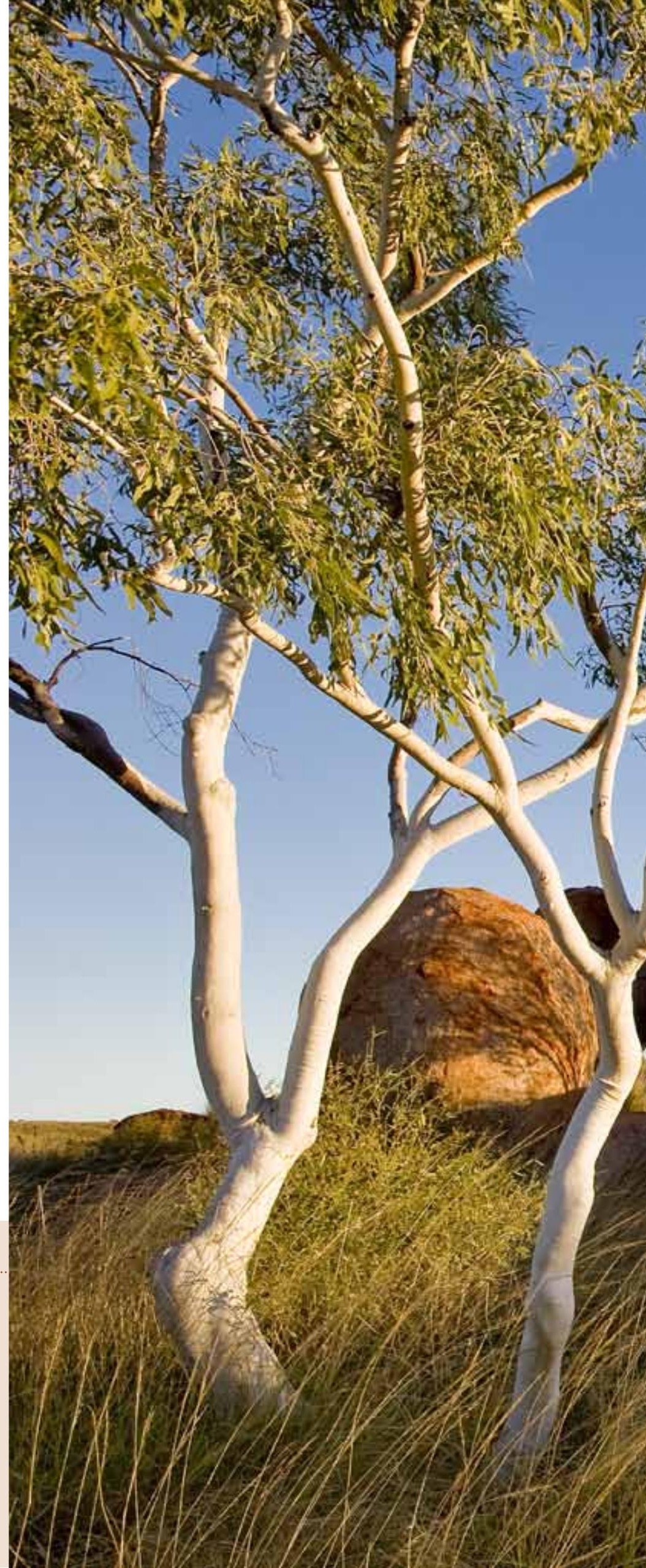


